\title{
A thrombotic snake in the thoracic aorta
}

\author{
Girolamo Catapano Minotti · Andrea Corsonello · \\ Giovanni Guadalupi $\cdot$ Raffaele Antonelli Incalzi
}

Received: 11 June 2009/Accepted: 2 July 2009/Published online: 23 July 2009

(C) SIMI 2009

\begin{abstract}
A 52-year-old woman was admitted to the surgery unit because of abdominal pain. She had a history of smoking (10 cigarettes/day), high blood pressure, and hypothyroidism. Her current drug regimen included L-thyroxine $100 \mu \mathrm{g} /$ day, ramipril $10 \mathrm{mg} /$ day, and atenolol $50 \mathrm{mg} /$ day. Routine blood examination revealed the presence of anemia ( $\mathrm{Hb} 8.3 \mathrm{~g} / \mathrm{dl}$, serum iron $10 \mu \mathrm{g} / \mathrm{dl}$, ferritin $5.46 \mathrm{ng} / \mathrm{ml}$ ), high ESR $(49 \mathrm{~mm})$ with normal PCR values $(0.36 \mathrm{mg} / \mathrm{dl})$ and coagulation tests, and negative occult fecal blood. Chest X-ray study revealed the presence of dilated aortic arch, and gastroscopic examination showed a hiatus hernia. Electrocardiogram and transthoracic echocardiography were normal, while transesophageal echocardiography disclosed a thrombotic formation (Fig. 1a, b) in the first tract of the descending aorta, which appeared as a "thrombotic snake" fluctuating in the lumen in the longitudinal projection (Fig. 1c-e). A CT scan confirmed the diagnosis of aortic thrombosis with an extension of about $7 \mathrm{~cm}$. Lower limb echo-color Doppler revealed occlusion of the popliteal artery and collateral revascularization of the tibial arteries. Abdominal pain was interpreted as ischemic in origin due to celiac-mesenteric hypoperfusion
\end{abstract}

G. Catapano Minotti · G. Guadalupi · R. Antonelli Incalzi

Fondazione San Raffaele, Cittadella della Carità,

Taranto, Italy

A. Corsonello ( $\square)$

Istituto Nazionale di Ricovero e Cura per Anziani (INRCA),

Viale della Resistenza Pal. Alfa Scala H, Rende,

87036 Cosenza, Italy

e-mail: andrea_corsonello@tin.it

R. Antonelli Incalzi

Università degli Studi Campus BioMedico, Rome, Italy or embolus, but completely resolved within few days from admission. The patient underwent an extensive screening for pro-thrombotic states that did not reveal any significant abnormality (plasma omocistein $7.55 \mathrm{nmol} / \mathrm{l}$, normal range 3.36-20.44; lupus anticoagulant negative; factor $\mathrm{V}$ mutation G1691A absent; factor II mutation G20210A absent; antithrombin III $111.5 \%$, normal range $70-120 \%$; protein C $112.5 \%$, normal range $70-120 \%$; protein S $105.7 \%$, normal range 60-120\%; activated protein $\mathrm{C}$ resistance $2.69 \%$, normal values $>2.00$; anti-cardiolipin $\operatorname{IgM} 5.4$, normal range 0.0-12.5; anti-cardiolipin $\operatorname{IgG} 9.9$, normal range $0.0-15.0$ ).

The patient had a cardiac surgery consultation, and was started on anticoagulation therapy. She was made aware of warning symptoms of peripheral or visceral emboli, and was recommended to seek immediately care at the Cardiovascular Department, if needed. She remained asymptomatic, and the thrombotic snake completely disappeared after 6 months of warfarin therapy. At the 6-month followup visit, hemoglobin levels were normal, and long-term anticoagulation was prescribed.

Thrombi may be observed in any aortic location, and their clinical presentation may vary widely with the localization. They are increasingly recognized in the last few years likely due to the widespread use of computed tomography, magnetic resonance imaging, and transesophageal echocardiography in diagnostic work-ups [1]. However, fluctuating aortic thrombi are distinctly rare $[1,2]$. Young age, smoking and family history of atherosclerotic disease seem to represent the most important risk factors [3], but fluctuating thrombi have been observed also in patients older than 60 years [2]. They usually complicate an aortic pathology, such as aneurysm, atherosclerotic plaque, or dissection [1], or a hypercoagulable defect [4], but spontaneous thrombi arising from a normal or simply 
Fig. 1 Transesophageal echocardiography showing the presence of thrombotic formations $(\mathbf{a}, \mathbf{b})$ in the first tract of the descending aorta (arrows), which appeared as a "thrombotic snake" fluctuating in the lumen in the longitudinal projection (c-e, arrows)
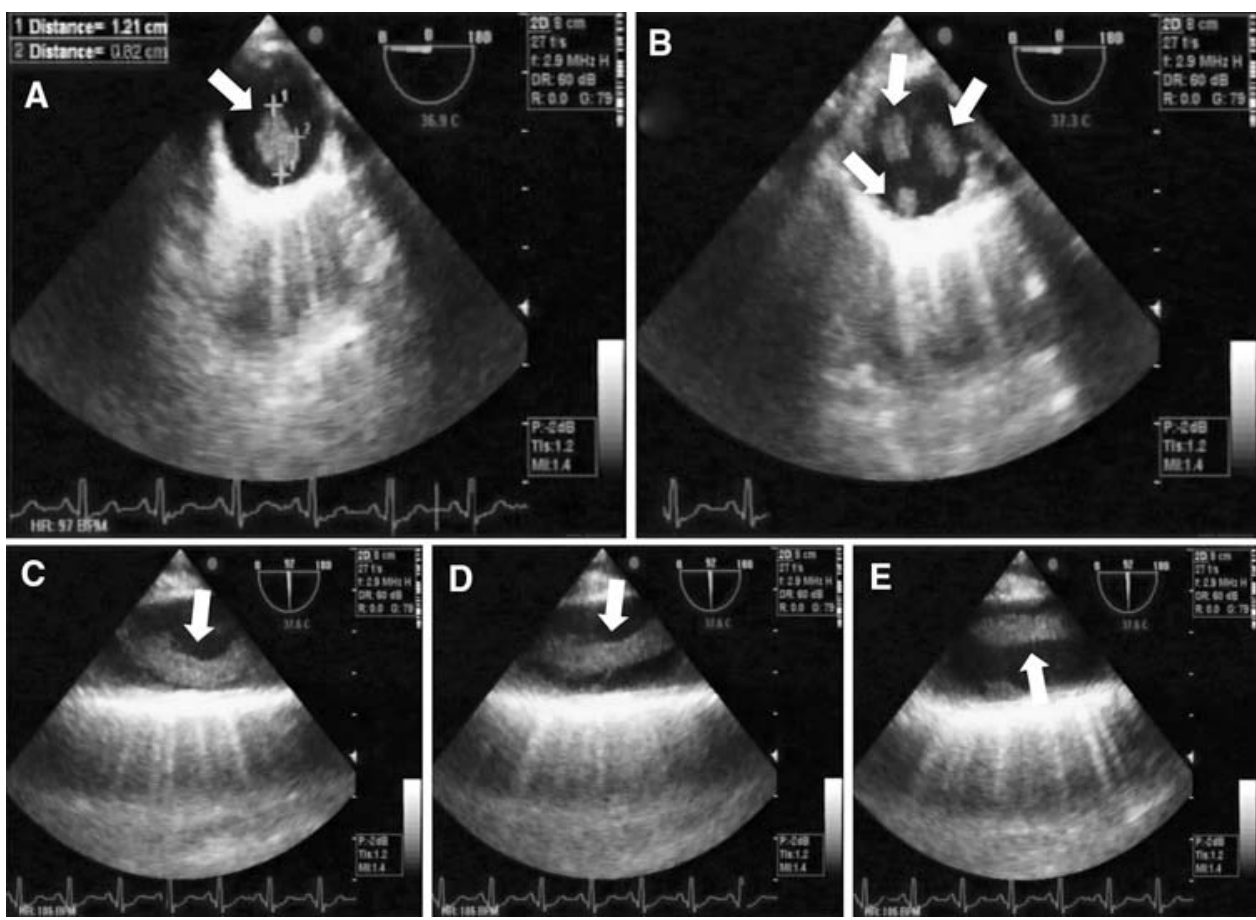

mildly irregular aortic wall, have been also described previously [5].

Although there is as yet no therapeutic standard for this condition, both systemic anticoagulation and surgical procedures are valuable therapeutic options $[1,2,6]$. However, the former is considered as the first line option, due to the high morbidity and mortality of surgical thrombectomy, as well as the high incidence of recurrences [2, 6, 7]. Surgery, instead, is advisable in the event of failure or thrombusrelated ischemic complications [2, 6]. Endovascular stent graft placement seems to represent a promising feasible, effective, and minimally invasive treatment alternative to open surgery procedures [7]. Whichever therapy is chosen, there is general consensus on the use of systemic anticoagulation to manage the long-term risk of thrombo-embolic complications or recurrence. Previously reported evidence, together with the rapid regression of abdominal pain, suggested a conservative medical approach in our patient.

Our case proves that aortic thrombosis can occur in the absence of a clearly identifiable hypercoagulable state, and that even a seemingly dreadful fluctuating aortic thrombus may resolve with anticoagulation, although its extent and mobility are consistent with a very high risk of embolic complications. The distinct paucity of information on natural history of this condition does not allow one to set the optimal duration of anticoagulation to prevent a new thrombosis. Based on general consensus, it seems sensible to recommend long-term anticoagulation to prevent a new lower limb or visceral arterial embolism.
Conflict of interest statement The authors declare that they have no conflict of interest related to the publication of this manuscript.

\section{References}

1. Rossi PJ, Desai TR, Skelly CL, Curi MA, Glagov S, Schwartz LB (2002) Paravisceral aortic thrombus as a source of peripheral embolization-report of three cases and review of the literature. J Vasc Surg 36:839-843

2. Choukroun EM, Labrousse LM, Madonna FP, Deville C (2002) Mobile thrombus of the thoracic aorta: diagnosis and treatment in 9 cases. Ann Vasc Surg 16:714-722

3. Laperche T, Laurian C, Roudaut R, Steg PG (1997) Mobile thromboses of the aortic arch without aortic debris. A transesophageal echocardiographic finding associated with unexplained arterial embolism. The Filiale Echocardiographie de la Societe Francaise de Cardiologie. Circulation 96:288-294

4. Dougherty MJ, Calligaro KD, Rua I, Delaurentis DA (2000) Idiopathic pedunculated mural thrombus of the nonaneurysmal infrarenal aorta presenting with popliteal embolization: two cases treated with thrombolytic therapy. J Vasc Surg 32:383-387

5. Hartwright D, Lagattolla NR, Taylor PR (1999) Recurrent systemic embolus secondary to free-floating thrombus in the descending thoracic aorta. Eur J Vasc Endovasc Surg 18:268-269

6. Piffaretti G, Tozzi M, Mariscalco G et al (2008) Mobile thrombus of the thoracic aorta: management and treatment review. Vasc Endovascular Surg 42:405-411

7. Luebke T, Aleksic M, Brunkwall J (2008) Endovascular therapy of a symptomatic mobile thrombus of the thoracic aorta. Eur J Vasc Endovasc Surg 36:550-552 